\title{
High Prevalence of Sarcopenia in Women with Osteoporotic Fractures
}

Candela Fernández, Beatriz Oliveri, Alicia Bagur, Dolores Gómez Glorioso, Diana González, Silvina Mastaglia and Carlos Mautalen*

Mautalen, Salud e Investigación, Buenos Aires, Argentina

*Corresponding author: Carlos Mautalen, Mautalen, Salud e Investigación, Buenos Aires, Argentina, Tel: +54 11-4514-3400; Fax: +54-11-48075661; E-mail: drmautalen@hotmail.com

Received date: June 14, 2016; Accepted date: August 12, 2016; Published date: August 19, 2016

Copyright: ( $) 2016$ Fernandez C, et al. This is an open-access article distributed under the terms of the Creative Commons Attribution License, which permits unrestricted use, distribution, and reproduction in any medium, provided the original author and source are credited.

\begin{abstract}
The aim of the present study was to assess the prevalence of sarcopenia in women with osteopenia/osteoporosis with or without fragility fractures.

Patients and methods: 112 ambulatory women with osteopenia/osteporosis were included. Body composition was determined by DXA. Weight, height, body mass index (BMI), bone mineral density (BMD) of the total skeleton, total lean mass (LM), appendicular lean mass (ALM) and the index: appendicular lean mass $/ \mathrm{height}^{2}\left(\mathrm{ALM} / \mathrm{h}^{2}\right)$ were determined. Grip strength and self-selected gait speed were assessed. Results: Average (X $\pm S D)$ results were: age $70.9 \pm 8.2$ years, BMI: $23.1 \pm 3.3 \mathrm{~kg} / \mathrm{h}^{2}$, total skeleton BMD T-Score: $-1.7 \pm 0.8$, total LM $33.3 \pm 3.8 \mathrm{~kg}$, ALM $14.4 \pm 2.1$ $\mathrm{kg}$ and $A L M / \mathrm{h}^{2}: 5.86 \pm 0.68 \mathrm{~kg} / \mathrm{h}^{2}$. Walking speed $0.96 \pm 0.21 \mathrm{~m} / \mathrm{s}$ and handgrip: $18.8 \pm 4.8 \mathrm{~kg}$. The prevalence of sarcopenia was: $24.7 \%$ (International Working Group criteria). Values for BMI, LM, ALM, ALM/h ${ }^{2}$, gait speed and hand grip were significantly lower in sarcopenic vs. non-sarcopenic patients. 29 patients, average age: $70.5 \pm 8.0$ years had osteoporotic fragility fractures $(\mathrm{Fx})$. The prevalence of sarcopenia in the group of patients with $\mathrm{Fx}$ was $41.4 \%$ vs. $19.3 \%$ in the non-Fx patients $(n=83)(p<0.018)$.

Conclusion: The prevalence of sarcopenia in women with osteopenia/osteoporosis was higher compared to that usually reported in non-selected patients of similar age. Those with bone fractures had a significantly higher prevalence of sarcopenia compared to the non-fracture patients. The assessment of muscle mass and function in patients with osteopenia/osteoporosis is recommended.
\end{abstract}

Keywords: Sarcopenia; Osteopenia; Osteoporosis; Fragility fractures; Vertebral fractures

\section{Introduction}

Sarcopenia, low muscle mass and physical performance, is important for the general health of the elderly and for the evolution of some frequent chronic illnesses. Sarcopenia also contributes to disability, reduced ability to cope with the stress of a major illness, and to mortality in the elderly. The assessment of its prevalence is of especial interest. This evaluation has been hindered by the lack of a uniform definition of the disease. However, there is an agreement that the evaluation should include assessment of the muscle mass as well as its function [1-3]. A recent report has studied the prevalence of sarcopenia in a large number of ambulatory Caucasian subjects over 65 years of age, free of significant comorbidities [4]. In women, prevalence was $11.8 \%$ using the International Working Group criteria (IWG) [1]. The frequency of sarcopenia is higher in patients with chronic diseases [5] or obesity [6]. On the other hand, there is an increased evidence on the Bone-Muscle interaction and, therefore, on the relationship of sarcopenia and osteoporosis $[7,8]$.

The aim of the present study was to assess the prevalence of sarcopenia in women among patients with osteopenia/osteoporosis with or without fragility fractures.

\section{Methods}

\section{Patients}

The results of 112 Caucasian ambulatory women, over 50 years, coming to our Clinic for the prevention/treatment of osteopenia/ osteoporosis between June 2014 and November 2015, were retrospectively analyzed and eligible for study inclusion. Patients with significant co-morbilities that cause secondary sarcopenia - such as COPD, severe chronic renal disease were not included. All these patients had a DXA evaluation of the lean mass. Gait speed and grip strength were also assessed.

All included patients had a BMD T-score below -1 SD, in total skeleton. Twenty nine patients have had a fragility bone fracture within the last 5 years in the following locations: vertebral 17 and nonvertebral 15 (wrist: 10, humerus: 2, pelvis: 2, hip: 1). Three of 29 patients had vertebral and non-vertebral fractures. None of the fractures were acute (last 4 months) and all were ambulatory at the time of the study.

\section{Measurements}

Body composition was determined by DXA. All measurements were performed with the same equipment (GE Lunar Prodigy software version 14.1, Madison, Wi, USA). Quality control was performed daily. As reported previously, coefficient of variation was $0.5 \%$ for $\mathrm{BMD}$, $0.8 \%$ for total lean mass and $4.8 \%$ for total fat mass [9].

Appendicular lean mass $/ \mathrm{h}^{2}$ values reported for 54 non-selected women in Buenos Aires, average age: 71 years old [10] were compared to values reported by Gould et al [11] for 121 Australian women aged 
70-79, showing similar mean values in both groups: $6.5 \pm 0.70 \mathrm{~kg} / \mathrm{m}^{2}$ and $6.6 \pm 0.76 \mathrm{~kg} / \mathrm{m}^{2}$ (p.n.s), respectively. Based on the similarity of these results, we have used in our patients the cut-off values, proposed by the above mentioned criteria [1].

The studied variables included weight, height, body mass index (BMI), bone mineral density (BMD) of the total skeleton, total fat mass, total lean mass and appendicular fat and lean mass (ALM). In addition, the index for appendicular lean mass (arms+legs) $/$ height $^{2}$ $\left(\mathrm{ALM} / \mathrm{h}^{2}\right)$ was determined.

Grip strength was measured using a dynamometer (Camry). The average of two measurements was recorded. Habitual gait speed was measured in a $5 \mathrm{~m}$ walk. Results were considered abnormal when below: $1 \mathrm{~m} / \mathrm{s}$ [1].

\section{Diagnostic criteria}

The term "sarcopenia" was used when a patient had an appendicular lean mass below: $5.67 \mathrm{~kg} / \mathrm{m}^{2}$ and the gait speed below $1 \mathrm{~m} / \mathrm{s}$ [1].

\section{Statistical Methods}

For continuous variables the averages were compared with the Student $\mathrm{t}$ test. Previously normal distribution was verified by the Shapiro-Wilks test and homogeneity of variance by the Bartlet test. To compare the proportion of sarcopenia in the patients with and without bone fractures, the homogeneity test for proportions was used. The Jisquare test was used to prove the null hypothesis of equality. In all cases $5 \%$ significance level was used.

\section{Results}

Average $(\mathrm{X} \pm \mathrm{SD})$ results for the total population $(\mathrm{n}=112)$ were: age $70.9 \pm 8.2$ years, weight $56.7 \pm 8.9 \mathrm{~kg}$, height $157 \pm 7 \mathrm{~cm}$, BMI: $23.1 \pm$ $3.3 \mathrm{~kg} / \mathrm{m}^{2}$, total skeleton BMD T-Score: $-1.7 \pm 0.8$, total fat mass: $21.3 \pm$ $6.7 \mathrm{~kg}$, total lean mass $33.3 \pm 3.8 \mathrm{~kg}$, ALM $14.4 \pm 2.1 \mathrm{~kg}$, appendicular fat mass $10.8 \pm 3.1 \mathrm{~kg}, \mathrm{ALM} / \mathrm{h}^{2}: 5.86 \pm 0.68 \mathrm{~kg} / \mathrm{h}^{2}$, walking speed $0.96 \pm$ $0.21 \mathrm{~m} / \mathrm{s}$ and handgrip: $18.8 \pm 4.8 \mathrm{~kg}$.

The prevalence of sarcopenia considering all patients was $24.7 \%$ (IWG criteria) (A similar result was obtained with the EWGSOP criteria: $23.9 \%)$.

Significant differences in body composition and muscle test between patients with or without sarcopenia (IWG criteria) were as follows: BMI $\left(\mathrm{kg} / \mathrm{m}^{2}\right) 22.01 \pm 3.72$ vs. $23.39 \pm 3.14 \mathrm{p}<0.05$, total lean mass $(\mathrm{kg})$ $31.32 \pm 4.04$ vs. $34.01 \pm 3.51 \mathrm{p}<0.001$, ALM (kg) $12.95 \pm 1.91$ vs. 14.89 $\pm 1.88 \mathrm{p}<0.001, \mathrm{ALM} / \mathrm{h}^{2}\left(\mathrm{~kg} / \mathrm{m}^{2}\right) 5.16 \pm 0.34$ vs. $6.09 \pm 0.60 \mathrm{p}<0.001$, gait speed $(\mathrm{m} / \mathrm{s}) 0.82 \pm 0.16$ vs. $1.01 \pm 0.21 \mathrm{p}<0.001$ and hand grip $(\mathrm{kg})$ $17.51 \pm 3.92$ vs. $19.26 \pm 5.08 \mathrm{p}<0.05$. No significant differences were observed in age, weight, height, total fat and BMD T-score of the total skeleton.

\section{Osteoporotic fractures}

29 patients with average age: $70.8 \pm 8.0$ years, BMI $24.1 \pm 3.9 \mathrm{~kg} / \mathrm{m}^{2}$, BMD T-score $-1.7 \pm 0.8$ had osteoporotic fragility fractures (Fx). Compared to the 83 patients without Fx, the ALM $/ h^{2}$ (5.64 \pm 0.69 vs. $\left.5.92 \pm 0.66 \mathrm{~kg} / \mathrm{h}^{2} \mathrm{p}<0.05\right)$ and hand grip $(17.55 \pm 4.90$ vs. $19.27 \pm 4.86$ $\mathrm{kg} \mathrm{p}<0.05)$ were significantly lower. Prevalence of sarcopenia was significantly higher in patients with fractures compared to the nonfracture group ( $41.4 \%$ vs. $19.3 \mathrm{p}<0.018)$ (Figure 1$)$.
The subgroup of patients with vertebral fractures $(n=17)$ had the following average $\pm 1 \mathrm{SD}$ : age $71.7 \pm 7.9$ years, BMI $25.1 \pm 4.1 \mathrm{~kg} / \mathrm{m}^{2}$, BMD T-score $-1.7 \pm 0.9$. Compared to the non-Fx patients, only hand grip $(17.26 \pm 4.0 \%$ vs. $19.27 \pm 4.86 \mathrm{p}<0.05)$ was significantly lower, while ALM $/ \mathrm{h}^{2}(5.65 \pm 0.61)$ only approached significance $(0.05>\mathrm{p}<0.1)$ Forty seven percent of them were sarcopenic ( $<<0.014$ compared to non-Fx patients).

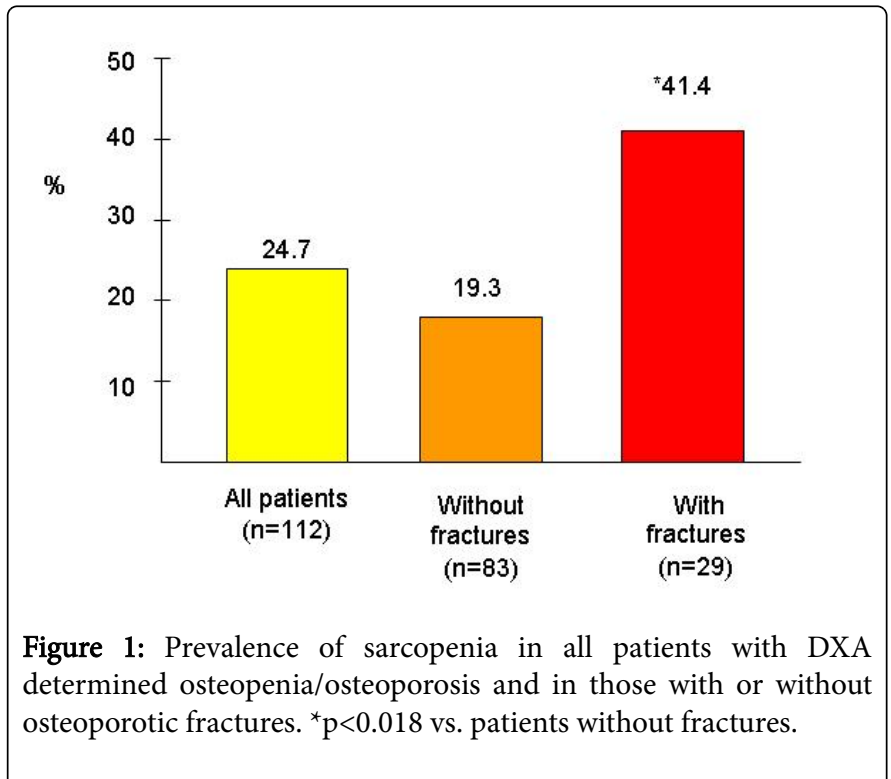

\section{Discussion}

Some authors have assessed the prevalence of sarcopenia but the studies reviewed had wide differences in their methodology $[2,12]$. Lately, Dam et al [4] have determined the prevalence of sarcopenia on a large population over 65 years of age, using 3 definitions of sarcopenia. The IWG diagnosis of Sarcopenia is based on the assessment of the $\mathrm{ALM} / \mathrm{h}^{2}$ and the walking speed [1]. The European Working Group adds the evaluation of hand grip to the above mentioned parameters [2]. Finally the FNIH definition is based on the assessment of the ALM/BMI plus walking speed and hand grip [3].

In women, the prevalence of sarcopenia was more than double compared with the results among men. In the former group, the results varied from only $2.3 \%$ (FNIH) (3) to $11.8 \%$ (IWG) [1] and $13.3 \%$ (EWGSOP) [2]. With similar methodologies to the two latter studies, prevalence among women of Asiatic origin was $7.6 \%$ in Korea [13] and $\sim 12 \%$ in two different studies from China $[14,15]$.

The prevalence of sarcopenia, observed in all patients with DXA determined osteopenia/osteoporosis of the present study, $24.7 \%$, is markedly higher than the results previously reported in the general population [4]. The results also showed that the frequency of sarcopenia is higher in women with osteopenia/osteoporosis even in the subgroup of those patients without fragility fractures in their previous history (19.3\%) (Figure 1).

The interest of the present study was also to assess the prevalence of sarcopenia in patients with fragility fractures and to compare the results with previously published results after hip or vertebral fractures. Considering all patients with fragility fractures (vertebral and nonvertebral $n=29$ ) in the present study, the prevalence of sarcopenia was 
41.4\%. Compared to the non-fracture group (prevalence of sarcopenia $19.3 \%)$, the difference was statistically significant $(\mathrm{p}<0.018)$.

Previous studies disclosed that after a hip fracture, the prevalence of sarcopenia varied from $\sim 58 \%$ to $68 \%[16,17]$ in women and $~ 74 \%$ in one study in men [17]. Thus, the prevalence of sarcopenia in patients with a hip fracture is probably $\sim 4$ to 5 times higher than among the general population.

Two articles [18,19] and the present study have assessed the prevalence of sarcopenia in women with vertebral fractures. With at least one vertebral fracture, prevalence varied from 33\% (18) to $42 \%$ [19]. In the latter study, prevalence was markedly higher than in the control group: $26 \%$. In our study, women with vertebral fractures had a sarcopenia prevalence of $47.1 \%$, against $19.5 \%$ in the nonfracture group ( $\mathrm{p}<0.014$ vs. non-Fx group).

The relation between sarcopenia with osteoporosis and fragility bone fractures has been examined recently $[8,20,21]$. Retrospective and prospective studies have supported its relationship. Several studies have sought to evaluate muscle mass in patients following a hip fracture. Lang et al. [22] found decreased muscle, measured in the Hounsfield unit scale, an indicator of intramuscular fat associated with increased risk of hip fractures.

In addition, other cross-sectional studies reported a relationship between lean mass and osteoporotic fractures at any site [23], and more specifically, that sarcopenic women had 2.7 times higher odds of having osteoporotic fractures and 2.1 times higher risk of falls than their non-sarcopenic counterparts [24].

Prospective studies have determined the risk of suffering fragility fractures in men with sarcopenia independently of BMD [25] and in patients of both sexes followed during 3.4 years [26]. The concomitant presence of low BMD and sarcopenia significantly increases the risk [26,27].

The present study has some limitations: the number of patients with fragility bone fractures is relatively small and only a small percentage of patients were obese (3.5\%) Based on all the aforementioned studies, simultaneous evaluation of sarcopenia and osteoporosis is potentially important to identify patients at higher risk of suffering an osteoporotic fracture and who need prevention and/or treatment for both conditions, as recently emphasized by Benkly and Cooper [28]. The herein reported results emphasize the need to evaluate the presence of sarcopenia also in patients with osteopenia/osteoporosis with or without osteoporotic fractures, to detect a risk factor for bone and general health. The results would permit to implement preventive strategies based on high protein diet, vitamin D administration and specific physical activity programs.

\section{Acknowledgement}

The secretarial assistance of Magdalena Esteche and the technical assistance of Analia Eduardo are gladfully acknowledged.

\section{References}

1. Fielding RA, Vellas B, Evans WJ, Bhasin S, Morley JE, et al. (2011) Sarcopenia: An undiagnosed condition in older adults. Current consensus definition: Prevalence, etiology and consequences. International working group on sarcopenia. J Am Med Dir Assoc 12: 249-256.

2. Cruz-Jentoft AJ, Baeyens JP, Bauer JM, Boirie Y, Cederholm T, et al. (2010) European working group on sarcopenia in older people. sarcopenia: European consensus on definition and diagnosis: Report of the European working group on sarcopenia in older people. Age and Ageing 39: 412-423.

3. Studenski SA, Peters KW, Alley DE, Cawthon PM, McLean RR, et al. (2014) The FNIH sarcopenia project: Rationale, study description, conference recommendations, and final estimates. J Gerontol A Biol Sci Med Sci 69: 547-558.

4. Dam TT, Peters KW, Fragala M, Cawthon PM, Harris TB, et al. (2014) An evidence-based comparison of operational criteria for the presence of sarcopenia. J Gerontol A Biol Sci Med Sci 69: 584-590.

5. Peterson SJ, Braunschweig CA (2016) Prevalence of sarcopenia and associated outcomes in the clinical setting. Nutr Clin Pract 31: 40-48.

6. Batsis JA, Mackenzie TA, Lopez-Jimenez F, Bartels SJ (2015) Sarcopenia, sarcopenic obesity and functional impairments in older adults: National Health and Nutrition Examination Surveys 1999-2004. Nutr Res 35: 1031-1039.

7. Reginster JY, Beaudart C, Buckinx F, Bruyère $\mathrm{O}$ (2016) Osteoporosis and sarcopenia: Two diseases or one? Curr Opin Clin Nutr Metab Care 19: 31-36.

8. Tarantino U, Piccirilli E, Fantini M, Baldi J, Gasbarra E, et al (2015) Sarcopenia and fragility fractures: Molecular and clinical evidence of the bone-muscle interaction. J Bone Joint Surg Am 97: 429-437.

9. Wittich A, Mautalen CA, Oliveri MB, Bagur A, Somoza F, et al. (1998) Professional football (Soccer) players have a markedly greater skeletal mineral content, density and size than age- and BMI- matched controls. Calcif Tissue Int 63: 112-117.

10. Mastaglia SR, Seijo M, Muzio D, Somoza J, Nuñez M, et al (2011) Effect of vitamin D nutritional status on muscle function and strength in healthy women aged over sixty-five years. J Nutr Health Agin 15: 349-354.

11. Gould H, Brennan SL, Kotowicz MA, Nicholson GC, Pasco JA (2014) Total and appendicular lean mass reference range for Australian men and women: The Geelong osteoporosis study. Calcif Tissue Int 94: 363-372.

12. Cruz-Jentoft AJ, Landi F, Schneider SM, Zúñiga C, Arai H, et al. (2014) Prevalence of and interventions for sarcopenia in ageing adults: A systematic review. Report of the International Sarcopenia Initiative (EWGSOP and IWGS). Age Ageing 43: 748-759.

13. Lee ES, Park HM (2015) Prevalence of sarcopenia in healthy Korean elderly women. J Bone Metab 22: 191-195.

14. Gao L, Jiang J, Yang M, Hao Q, Luo L, et al (2015) Prevalence of sarcopenia and associated factors in Chinese community-dwelling elderly: Comparison between rural and urban areas. J Am Med Dir Assoc 16: 1003.

15. Han P, Kang L, Guo Q, Wang J, Zhang W, et al. (2016) Prevalence and factors associated with sarcopenia in suburb-dwelling older Chinese using the Asian working group for sarcopenia definition. J Gerontol A Biol Sci Med Sci 71: 529-535.

16. Di Monaco M, Castiglioni C, De Toma E, Gardin L, Giordano S, et al. (2015) Presarcopenia and sarcopenia in hip-fracture women: Prevalence and association with ability to function in activities of daily living. Aging Clin Exp Res 27: 465-472.

17. Ho AW, Lee MM, Chan EW, Ng HM, Lee CW, et al. (2016) Prevalence of pre-sarcopenia and sarcopenia in Hong Kong Chinese geriatric patients with hip fracture and its correlation with different factors. Hong Kong Med J 22: 23-29.

18. Iolascon G, Giamattei MT, Moretti A, Di Pietro G, Gimigliano F, et al. (2013) Sarcopenia in women with vertebral fragility fractures. Aging Clin Exp Res 25: S129-131.

19. Hida T, Shimokata H, Sakai Y, Ito S, Matsui Y, et al. (2015) Sarcopenia and sarcopenic leg as potential risk factors for acute osteoporotic vertebral fracture among older women. Eur Spine J.

20. Oliveira A, Vaz C. (2015) The role of sarcopenia in the risk of osteoporotic hip fracture. Clin Rheumatol 34: 1673-1680.

21. He H, Liu Y, Tian Q, Papasian CJ, Hu T, et al. (2016) Relationship of sarcopenia and body composition with osteoporosis. Osteo Int 27: 473-482. 
Citation: Fernández C, Oliveri B, Bagur A, Glorioso DG, González D, et al. (2016) High Prevalence of Sarcopenia in Women with Osteoporotic Fractures. J Osteopor Phys Act 4: 181. doi:10.4172/2329-9509.1000181

Page 4 of 4

22. Lang T, Cauley JA, Tylavsky F, Bauer D, Cummings S, et al. (2010) Computed tomographic measurements of thigh muscle cross-sectional area and attenuation coefficient predict hip fracture: The health, aging, and body composition study. J Bone Miner Res 25: 513-519.

23. Capozza RF, Cure-Cure C, Cointry GR, Meta M, Cure P, et al (2008) Association between low lean body mass and osteoporotic fractures after menopause. Menopause 15: 905-913.

24. Sjöblom S, Suuronen J, Rikkonen T, Honkanen R, Kröger H, et al (2013) Relationship between postmenopausal osteoporosis and the components of clinical sarcopenia. Maturitas 75:175-180.

25. Yu R, Leung J, Woo J (2014) Incremental predictive value of sarcopenia for incident fracture in an elderly Chinese cohort: Results from osteoporotic fractures in men (MrOS) study. J Am Med Dir Assoc 15: 551-558.

26. Hars M, Biver E, Chevalley T, Herrmann F, Rizzoli R, et al. (2016) Low lean mass predicts incident fractures independently from FRAX: A prospective cohort study of recent Retirees. J Bone Miner Res.

27. Chalhoub D, Cawthon PM, Ensrud KE, Stefanick ML, Kado DM, et al (2015) Osteoporotic fractures in men study research group. Risk of Nonspine Fractures in Older Adults with Sarcopenia, Low Bone Mass, or Both. J Am Geriatr Soc. 63:1733-1740.

28. Binkley N and Cooper C (2015) Sarcopenia, the next frontier in fracture prevention: Introduction from the guest editors. J Clin Densitom 18: 459-460. 